Sven Beck · Bernhard Schink

\title{
Acetate oxidation through a modified citric acid cycle in Propionibacterium freudenreichii
}

Received: 18 October 1994 / Accepted: 6 December 1994

\begin{abstract}
Propionibacterium freudenreichii strain DSM 20271 was grown in a mineral medium containing $0.1 \%$ $(\mathrm{w} / \mathrm{v})$ yeast extract. Acetate was oxidized by growing cells with potassium hexacyanoferrate as electron acceptor, which was oxidized by a three-electrode poised-potential system at a redox potential of $+510 \mathrm{mV}$. Growth with acetate under these conditions followed linear rather than exponential kinetics, whereas growth with other substrates such as lactate under the same conditions was exponential. Cell-free extracts of $P$. freudenreichii cells grown with acetate contained all enzymes of the classical citric acid cycle except 2-oxoglutarate-oxidizing activity. No activity of anaplerotic reactions such as isocitrate lyase or malate synthase was found. Instead, moderate activities of glutamate decarboxylase, 4-aminobutyrate:2oxoglutarate aminotransferase, and succinate semialdehyde dehydrogenase were detected. In short-term radiolabeling experiments with $\mathrm{U}-{ }^{14} \mathrm{C}$-acetate, 4 -aminobutyrate was identified as a major early intermediate in acetate oxidation by these cells. These findings allow the construction of a modified citric acid cycle that compensates the lack of 2-oxoglutarate dehydrogenase by a subcycle through glutamate, 4-aminobutyrate, and succinate semialdehyde. Lack of anaplerotic reactions explains subexponential growth kinetics during growth with acetate.
\end{abstract}

Key words Citric acid cycle - Propionibacterium freudenreichii - 2-Oxoglutarate dehydrogenase . Glutamate decarboxylase - 4-Aminobutyrate $\cdot$ Succinate semialdehyde

\section{Introduction}

Members of the genus Propionibacterium are primarily fermenting bacteria with a tendency towards micro-

S. Beck · B. Schink (ه)

Fakultät für Biologie, Universität Konstanz,

Postfach 5560, D-78434 Konstanz, Germany

Tel. +49-7531-882140; Fax +49-7531-882966

e-mail bernhard.schink@uni-konstanz.de aerophilic oxygen reduction. Several species have been reported to be able to couple oxidation of sugars or lactate also with reduction of nitrate to nitrite (DeVries et al. 1973; Van Gent-Ruyters et al. 1976; Wood 1981). Reduction of an external electron acceptor by $P$. pentosaceum causes a shift of the fermentation pattern from propionate to enhanced acetate formation, and acetate is slowly oxidized further (Van Gent-Ruyters et al. 1975). A similar effect of fermentation shift has been observed in growth experiments with Propionibacterium freudenreichii in the presence of potassium hexacyanoferrate as oxidant, which is reoxidized electrochemically in a three-electrode poised-potential culture system (Emde and Schink 1990). Propionate is also completely oxidized to acetate and $\mathrm{CO}_{2}$ in such cultures, thus proving that the propionate-forming pathway in these bacteria is entirely reversible (Emde and Schink 1990). At the end of this conversion, part of the formed acetate appears to be oxidized further.

The present communication documents this acetate oxidation capacity and provides a first reliable proof of the function of a modified citric acid cycle in these bacteria.

\section{Materials and methods}

Bacteria and cultivation

Propionibacterium freudenreichii ssp. freudenreichii (DSM 20271) was obtained from the Deutsche Sammlung von Mikroorganismen GmbH, Braunschweig, Germany.

For all growth experiments, carbonate-buffered mineral medium with $0.2 \mathrm{~g} \mathrm{KH}_{2} \mathrm{PO}_{4}, 0.25 \mathrm{~g} \mathrm{NH}_{4} \mathrm{Cl}, 3.0 \mathrm{~g} \mathrm{NaCl}, 0.4 \mathrm{~g} \mathrm{MgCl}_{2} \cdot 6 \mathrm{H}_{2} \mathrm{O}$, $0.5 \mathrm{~g} \mathrm{KCl}, 0.15 \mathrm{~g} \mathrm{CaCl}_{2} \cdot 2 \mathrm{H}_{2} \mathrm{O}$, and $0.07 \mathrm{~g} \mathrm{Na}_{2} \mathrm{SO}_{4}$ per liter was prepared, autoclaved, and supplemented with yeast extract $(1.0 \mathrm{~g}$ $1^{-1}$ final concentration), vitamins, and trace elements as described carlier (Emde and Schink 1990). Bacteria were cultivated either in screw-cap bottles or serum flasks, or in the presence of regulated electrodes in a three-electrode poised-potential cultivation system described previously (Emde et al. 1989). This system allows maintenance of a fixed redox potential through electrochemical electron supply or removal, and control of electron flow in either direction. Growth was measured via turbidity with an Eppendorf photometer at $578 \mathrm{~nm}$. 


\section{Chemical determinations}

Acetate and other fatty acids were determined by gas chromatography (Dehning and Schink 1989), and hexacyanoferrate(III) was measured spectrophotometrically at $419 \mathrm{~nm}$ (Emde and Schink 1990). Protein was quantified according to the method of Bradford (1976), with bovine serum albumin as standard.

\section{Enzyme assays}

Enzymes were assayed in cell-free extracts of cells grown either in bottle cultures or in the electrode culture system mentioned above. Cells were broken by sonication (Bransonic 52, Danbury, Conn., USA) with or without pretreatment with lysozyme [70 $\mathrm{mg}$ ( $\mathrm{mg}$ cell protein $)^{-1}$ I for $2 \mathrm{~h}$ at $25^{\circ} \mathrm{C}$. After removal of cell debris by centrifugation at $5,000 \times g$, the extract was kept on ice until used.

Glucose-6-phosphate dehydrogenase (EC 1.1.1.49), 6-phosphogluconate dehydrogenase (EC 1.1.1.44), citrate synthase (EC 4.1.3.7), acetate kinase (EC 2.7.2.1), phosphate acetyltransferase (EC 2.3.1.8), and malate dehydrogenase (EC 1.1.1.37) were assayed according to Bergmeyer (1974), carbon monoxide dehydrogenase (EC 1.2.99.2) according to Diekert et al. (1978), and succinate semialdehyde dehydrogenase (EC 1.2.1.16) according to Jakoby (1962).

Isocitrate lyase (EC 4.1.3.1) and malate synthase (EC 4.1.3.2) were determined according to Dixon and Kornberg (1959), aconitase (EC 4.2.1.3) according to Anfinsen (1955), isocitrate dehydrogenase (EC 1.1.1.42) according to Bernt and Bergmeyer (1974), succinyl-CoA synthetase (EC 6.2.1.4) according to Riddles et al. (1979), succinate dehydrogenase (EC 1.3.99.1) according to Stams et al. (1984), and fumarase according to Brandis-Heep et al. (1983). Determination of the pyruvate dehydrogenase complex (EC 1.2.4.1) and its first subunit followed the procedure of Reed and Mukherjee (1969) with many modifications; an analogous approach was tried for 2-oxoglutarate dehydrogenase (modified from Shiio and Ujigawa-Takeda 1980). Modifications included addition of glycerol up to $50 \%(\mathrm{v} / \mathrm{v})$, variation of the buffer system and the prevailing $\mathrm{pH}$, variation of the reducing agent, and use of $\mathrm{NADP}^{+}$, 3-acetylpyridine adenine dinucleotide (APAD), dichlorophenol indophenol, or benzyl viologen as electron acceptor, instead of $\mathrm{NAD}^{+}$. 2-Oxoglutarate synthase (EC 1.2.7.3) was measured according to Zeikus et al. (1977). Glutamate decarboxylase (EC 4.1.1.15; according to Fonda 1985) and 2-oxoglutarate decarboxylase (according to Kapol et al. 1990) were measured as $\mathrm{CO}_{2}$ release reactions by gas chromatography (Platen and Schink 1990).

4-Aminobutyrate: 2-oxoglutarate aminotransferase (EC 2.6.1.19) was assayed in a coupled test system including the succinate semialdehyde dehydrogenase activity present in the cell extract. The test mixture contained in $50 \mathrm{mM}$ triethanolamine buffer, $\mathrm{pH} 7.9$ (final concentrations): $20 \mathrm{uM}$ mercaptoethanol, $1 \mathrm{mM} \mathrm{NADP}^{+}$, 0-1 $\mathrm{mM}$ pyridoxalphosphate, $20 \mathrm{mM}$ 2-oxoglutarate, $20 \mathrm{mM} \mathrm{4-}$ aminobutyrate, and $10-100 \mu \mathrm{I}$ cell-free extract per $\mathrm{ml}$ reaction mixture. The reaction was started with either 2-oxoglutarate or 4aminobutyrate; pyruvate or glutamate was used as alternative substrates to check for specificity. The identity of the products formed was verified by HPLC (Brune and Schink 1990) on a Merck LiChrospher $100 \mathrm{RP} 18$ ( $5 \mu \mathrm{m}, 250-4 \mathrm{~mm}$ end-capped column) with $100 \mathrm{mM}$ ammonium phosphate buffer $(\mathrm{pH} \mathrm{2.6)}$. Under these separation conditions, 2-oxoglutarate and succinate semialdehyde appeared after 3.7 and $5.3 \mathrm{~min}$, respectively.

\section{Labelling experiments}

Cells were grown with acetate in the presence of $0.5 \mathrm{mM}$ potassium hexacyanoferrate(III) in the three-electrode culture system described. Cells were harvested by centrifugation $(5,000 \times g, 20$ $\min$, washed twice in the absence of oxygen in acetate-free growth medium without yeast extract, and resuspended to a dense suspension $(500 \mathrm{ul})$ in the same medium in the presence of $6 \mathrm{mM}$ $\mathrm{K}_{3}\left[\mathrm{Fe}(\mathrm{CN})_{6}\right]$ in a $\mathrm{N}_{2}$-flushed serum vial sealed with a butyl rubber stopper. The suspension was stirred magnetically at $25^{\circ} \mathrm{C}$, and the reaction was started by addition of $390 \mathrm{kBq} \mathrm{U}-{ }^{14} \mathrm{C}$-acetate diluted in $0.5 \mathrm{mM}$ non-labeled sodium acetate (final concentration). Samples $(100 \mu \mathrm{l})$ were taken after $0.5,1,5,10$, and $30 \mathrm{~min}$ with a syringe and the reaction was stopped immediately in an Eppendorf tube containing $1 \mathrm{ml}$ boiling $98 \%$ ethanol. After two centrifugation runs $(15,000 \times g, 5 \mathrm{~min}$ each) including aqueous extraction of the cell pellet, the supernatant was collected and condensed to $20 \mu \mathrm{l}$ volume, and stored at $-20^{\circ} \mathrm{C}$. Volumes of $5-15 \mu \mathrm{l}$ were applied to dried thin-layer plates $(20 \times 20 \mathrm{~cm})$ with a $0.5 \mathrm{~mm}$ cellulose $\mathrm{MN}$ 300 layer (Macherey and Nagel, Düren, Germany), and separated in one dimension by electrophoresis, in the other direction by chromatography in two steps with intermediate drying (Schürmann 1969). After drying for at least $12 \mathrm{~h}$, labeled spots were visualized by autoradiography for 15-22 days (X-ray film Curix RP1, AgfaGevaert, Leverkusen, Germany) and subsequent development according to the producer's recommendations. Labeled compounds were identified by comparison with reference compounds separated under identical conditions and visualized by staining with bromocresol green solution (Bryant and Overell 1953).

\section{Chemicals}

All chemicals were of analytical grade and were obtained from Fluka (Neu-Ulm, Germany), Sigma (Deisenhofen, Germany), Boehringer (Mannheim, Germany), and Merck (Darmstadt, Germany). Radioactive $\mathrm{U}^{1}{ }^{14} \mathrm{C}$-acetate $\left(2.7 \mathrm{GBq} \mathrm{mmol}^{-1}\right)$ was purchased from ICN Chemicals (Meckenheim, Germany).

\section{Results}

Growth of Propionibacterium freudenreichii with acetate

Propionibacterium freudenreichii cells pregrown by fermentation of $20 \mathrm{mM}$ lactate were harvested at the late exponential growth phase, washed once with growth medium, resuspended, and transferred into the three-electrode poised-potential culture vessel, at an initial OD of 0.56 . The time course of acetate oxidation at $E^{\prime}=+510$ $\mathrm{mV}$ is documented in Fig. 1. Acetate was oxidized completely to $\mathrm{CO}_{2}$, and the equivalent amount of electrons was transferred stoichiometrically via hexacyanoferrate to the working electrode (electron balance product/substrate after correction for background yeast extract oxidation: $104.7 \%$ ). The current of electron transfer increased to a maximum at the beginning of acetate oxidation and dropped abruptly with acetate exhaustion. Acetate oxidation and cell density increase followed linear rather than exponential kinetics, indicating that a key catalyst in this metabolism was not multiplied. If experiments were started with a cell density of at least $O D=0.5,10 \mathrm{mM}$ acetate was completely oxidized. If the experiment was started with cell suspensions of substantially lower density (OD $<0.2$ ), acetate oxidation ceased before complete substrate exhaustion. The cell yield obtained depended on the amount of acetate provided; maximal values were obtained with $5 \mathrm{mM}$ acetate (23.4-28.4 g dry mass per mol acetate). Iron (III) hydroxide or iron (III) citrate could not serve as electron acceptor for acetate oxidation.

To determine first whether a citric acid cycle is involved in acetate oxidation, the aconitase inhibitor 2-fluoroacetate was added to an acetate-oxidizing culture. As Fig. 2 documents, oxidation of acetate, cell density increase, and electron transfer to the working electrode 


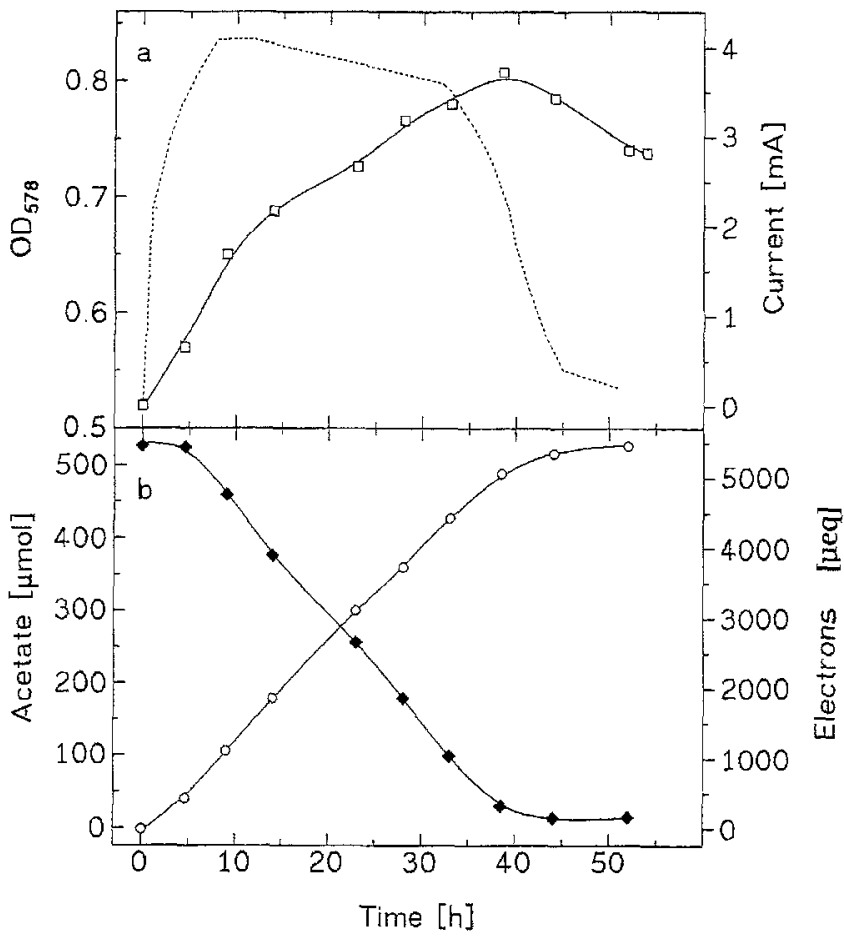

Fig. 1 Growth of Propionibacterium freudenreichii with $5 \mathrm{mM}$ acetate and $5 \mathrm{mM}$ potassium hexacyanoferrate in the presence of regulated electrodes at a redox potential of $+510 \mathrm{mV}$ (open squares optical density, dashed lines current, open circles amount of electrons transferred to the working electrode, filled diamonds acetate)

ceased immediately upon addition of fluoroacetate. A control run with water addition was not influenced. Interestingly, addition of lactate restituted growth and electron release immediately, indicating that only acetate metabolism was impaired by fluoroacetate addition.

\section{Biochemistry of acetate oxidation}

In cell-free extracts of $P$. freudenreichii cells grown with acetate and potassium hexacyanoferrate, all enzymes of the classical tricarboxylic acid cycle were measured at activities sufficient to account for the measured acetate oxidation rates [max. $13.2 \mathrm{nmol} \mathrm{min}{ }^{-1}$ (mg protein) $)^{-1}$ ] except for 2-oxoglutarate dehydrogenase activity (Table 1). Numerous efforts to modify the assay conditions or to check for alternative enzymes (2-oxoglutarate synthase, 2-oxoglutarate decarboxylase) were unsuccessful. Pyruvate dehydrogenase was assayed for comparison and was found at low, but reliable activity with hexacyanoferrate as electron acceptor. No activity of carbon monoxide dehydrogenase (acetyl-CoA synthase) was found. As a further alternative, enzymes of a possible "reversed pentose phosphate cycle" (glucose-6-phosphate dehydrogenase, 6phosphogluconate dehydrogenase) were assayed and were found to be very low (Table 1). In addition, no activity of the anaplerotic reactions of the citric acid cycle, isocitrate lyase and malate synthase, was found.

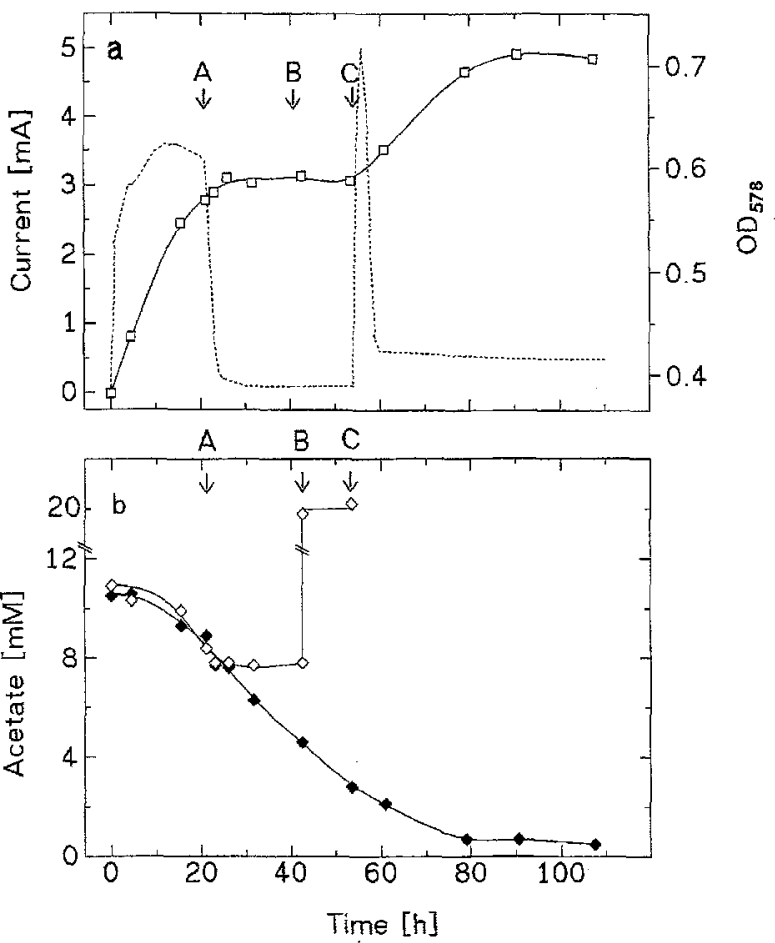

Fig. 2A-C Influence of fluoroacetate on Propionibacterium freudenreichii growing with $10 \mathrm{mM}$ acetate and $5 \mathrm{mM}$ potassium hexacyanoferrate in the presence of regulated electrodes (open squares optical density, dashed lines current, open diamonds acetate, filled diamonds acetate in an experiment without addition of fluoroacetate). A Addition of $1 \mathrm{ml} 100 \mathrm{mM}$ fluoroacetate (sterile water in the control experiment), $\mathbf{B}$ addition of $12 \mathrm{mM}$ acetate, $\mathrm{C}$ addition of $2.5 \mathrm{mM}$ lactate

After indications of a possible participation of 4 aminobutyrate in acetate oxidation were obtained (see below), we checked for a 2-oxoglutarate-oxidizing activity involving amination. Activities of 2-oxoglutarate: 4-aminobutyrate transaminase, glutamate decarboxylase, and succinate semialdehyde dehydrogenase were found at sufficient activities (Table 1). The identity of 4-aminobutyrate formed from glutamate in the presence of succinate semialdehyde was proven in parallel experiments with discontinuous analysis of substrates and products by HPLC. 2Oxoglutarate: 4-aminobutyrate aminotransferase activity was slightly enhanced by addition of pyridoxalphosphate (20\% increase at maximum with $100 \mu \mathrm{M}$ pyridoxalphosphate).

As a further approach to elucidate the acetate degradation pathway, we tried short-term labeling experiments with labeled acetate. The compounds labeled after 30-s incubation of active cells with $\mathrm{U}-{ }^{14} \mathrm{C}$-acetate are shown in Fig. 3. Strong labeling was found in citric acid cycle intermediates and their amination derivatives, such as citrate/ isocitrate, succinate, fumarate, malate, aspartate, asparagine, and glutamate, and in the oxaloacetate product pyruvate. To our surprise, 4-aminobutyrate was also an early labeled product in acetate oxidation by $P$. freudenreichii cells, in accordance with the enzyme measurements mentioned above. 
Table 1 Specific activities of enzymes measured in cell-free extracts of $P$. freudenreichii after growth with $5 \mathrm{mM}$ acetate and $5 \mathrm{mM}$ potassium hexacyanoferate in the presence of regulated electrodes. Numbers represent means of at least two independent determinations in every case a NADP-dependent

${ }^{b}$ Low nonspecific, nonprotein-dependent activity in crude extract preparations

${ }^{c}$ With hexacyanoferrate as electron acceptor

\begin{tabular}{|c|c|c|}
\hline Enzyme & EC-number & $\begin{array}{l}\text { Specific activity } \\
\text { nmol } \min ^{-1}(\mathrm{mg} \text { protein })^{-1}\end{array}$ \\
\hline Acetate kinase & $\mathrm{EC} 2.7 .2 .1$ & 3530 \\
\hline Phosphate acetyltransferase & $\mathrm{EC} 2.3 .1 .8$ & 6050 \\
\hline Citrate synthase & $\mathrm{EC} 4.1 .3 .7$ & 460 \\
\hline Aconitate hydratase & EC 4.2.1.3 & 18 \\
\hline Isocitrate dehydrogenase ${ }^{a}$ & $\mathrm{EC} 1.1 .1 .42$ & 135 \\
\hline Succinyl-CoA synthetase & EC 6.2.1.4 & 19 \\
\hline Succinate dehydrogenase & $\mathrm{EC} 1.3 .99 .1$ & 10 \\
\hline Fumarate hydratase & EC 4.2.1.2 & 99 \\
\hline Malate dehydrogenase & EC 1.1.1.37 & 13890 \\
\hline Glutamate decarboxylase & $\mathrm{EC} 4.1 .1 .15$ & $18-29$ \\
\hline Succinate semialdehyde dehydrogenase ${ }^{a}$ & $\mathrm{EC} 1.2 .1 .16$ & 117 \\
\hline 4-Aminobutyrate-2-oxoglutarate aminotransferase & EC 2.6.1.19 & 65 \\
\hline 2-Oxoglutarate dehydrogenase & EC 1.2.4.2 & $<1^{b}$ \\
\hline Pyruvate dehydrogenase ${ }^{c}$ & EC 1.2.4.1 & 37 \\
\hline 2-Oxoglutarate decarboxylase & $\mathrm{EC} ?$ & $<1^{\mathrm{b}}$ \\
\hline Carbon monoxide dehydrogenase & EC 1.2.99.2 & $<1^{\mathrm{b}}$ \\
\hline Isocitrate lyase & EC 4.1.3.1 & $<1$ \\
\hline Malate synthase & EC 4.1.3.2 & $<1$ \\
\hline Glucose-6-phosphate dehydrogenase & $\mathrm{EC} 1.1 .1 .49$ & 18 \\
\hline 6-Phosphogluconate dehydrogenase & EC 1.1.1.44 & 47 \\
\hline
\end{tabular}

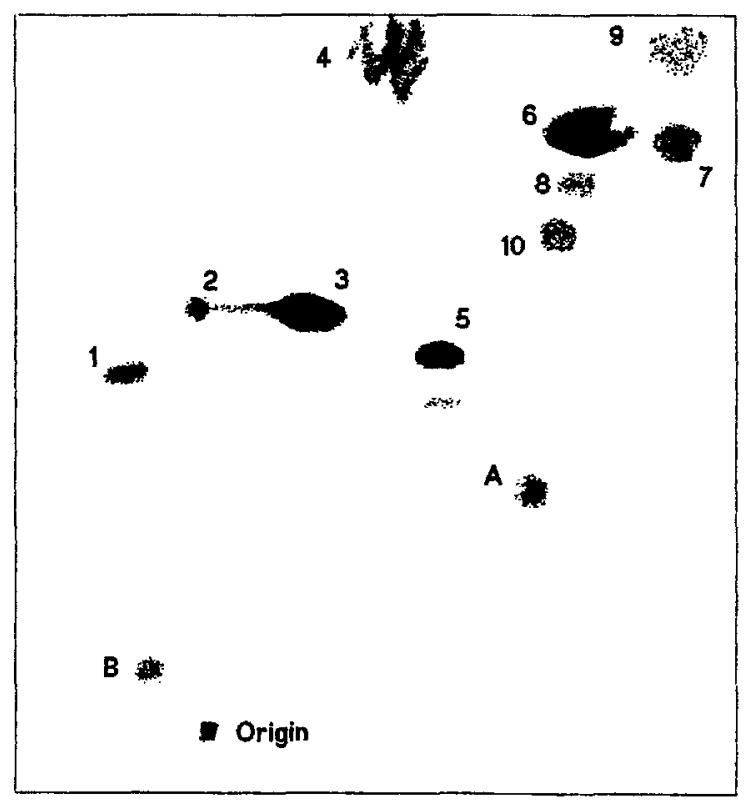

Fig. 3 Autoradiographic analysis of the water-soluble products formed by Propionibacterium freudenreichii cells after incubation (30 s) with $\mathrm{U}^{14} \mathrm{C}$-acetate ( 1 asparagine, 24 -aminobutyrate, 3 glutamate, 4 succinate, 5 aspartate, 6 glycolate/malate, 7 pyruvate, 8 citrate/isocitrate, 9 fumarate, 10 glycerate, $A, B$ non-identified products)

\section{Discussion}

Acetate oxidation by Propionibacterium sp.

The present study documents that acetate can be oxidized completely to $\mathrm{CO}_{2}$ by a member of the genus Propionibacterium, which is usually considered to excrete acetate as an oxidized fermentation product. Although $\mathrm{CO}_{2}$ was not quantified in our bicarbonate-buffered growth medium, the electron balance could be measured exactly by the electrode cultivation system employed. Indications of acetate oxidation by such bacteria have been published earlier (Delwiche and Carson 1953; Bonartseva et al. 1973), but substrate conversion with nitrate as oxidant was poorly reproducible due to accumulation of toxic nitrite that was not reduced further. Coupling of substrate oxidation to reduction of potassium hexacyanoferrate(III) in our electrodecoupled culture system in earlier experiments allowed incomplete oxidation of, for example, glycerol, lactate or propionate to acetate and $\mathrm{CO}_{2}$, by $P$. freudenreichii with concomitant exponential growth (Emde and Schink 1990). In contrast, acetate oxidation in this system occurred with linear or even sublinear kinetics as documented in this study; obviously, a key intermediate or catalyst did not multiply during growth. As a result, the cell mass was able to double at most only once with acetate as electron donor.

The ecophysiological significance of this oxidation capacity of a propionic bacterium is not obvious. Free iron oxides such as $\mathrm{Fe}(\mathrm{OH})_{3}$ were not reduced by $P$. freudenreichii cells. Obviously, acetate oxidation can operate only as an intermediate means of energy generation in the presence of, for example, nitrate or low amounts of oxygen if other electron donors are lacking; long-term maintenance of growth with this substrate combination is hampered by exhaustion of a reaction intermediate (see below).

Biochemistry of acetate oxidation by Propionibacterium freudenreichii

Analysis of enzymes in cell-free extracts of acetate-grown cells gave no indication of enzymes of the carbon monox- 


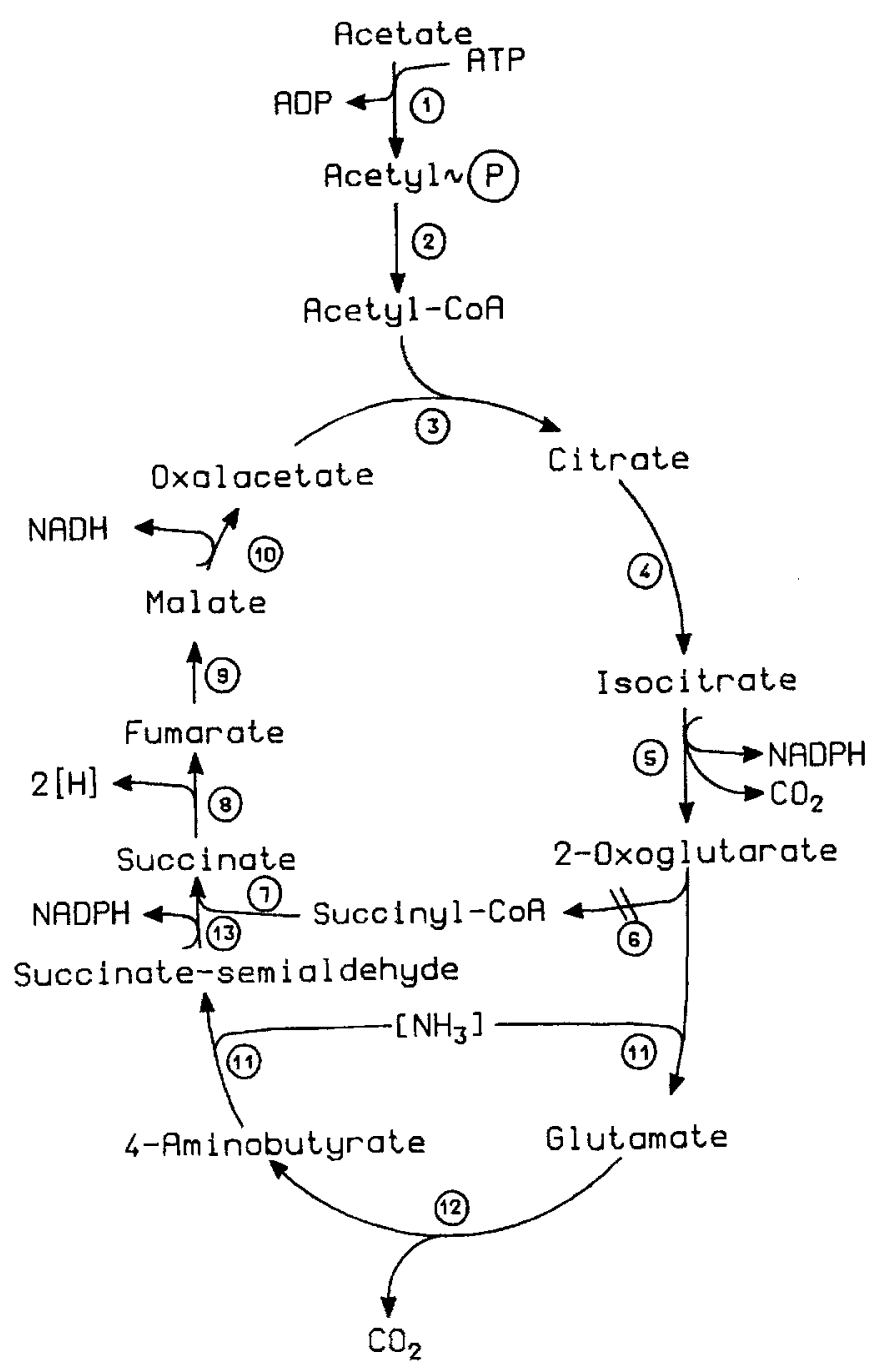

Fig.4 Pathway of acetate oxidation by $P$. freudenreichii as suggested by our results. Enzymes involved: $l$ acetate kinase, 2 phosphate acetyltransferase, 3 citrate synthase, 4 aconitase, 5 isocitrate dehydrogenase, 6 2-oxoglutarate dehydrogenase, 7 succinyl-CoA synthetase, 8 succinate dehydrogenase, 9 fumarate dehydrogenase, 10 malate dehydrogenase, 11 4-aminobutyrate: 2-oxoglutarate aminotransferase, 12 glutamate decarboxylase, 13 succinate semialdehyde dehydrogenase

ide dehydrogenase (Wood) pathway of acetate oxidation (Schauder et al. 1986). The enzymes of the pentose phosphate cycle were present (Stjernholm and Flanders 1962; Wood 1981) and could perhaps operate in reverse to oxidize acetate. However, this would require reversal of the phosphoketolase reaction, which is highly exergonic in the direction of acetate formation $\left(\Delta \mathrm{G}_{0}^{\prime}=-44 \mathrm{~kJ}\right.$ per mol reactant). This reaction as studied in lactic acid bacteria has so far proven to be irreversible (Heath et al. 1958), thus precluding the use of this pathway for acetate oxidation.

Instead, we found good-to-moderate activities of most of the citric acid cycle enzymes, except for 2-oxoglutarate dehydrogenase, in accordance with earlier studies in our laboratory (Rosner et al. 1990). Earlier reports on acetate oxidation by $P$. freudenreichii and $P$. shermanii claimed the presence also of 2-oxoglutarate dehydrogenase activity. However, these claims were based either on oxidation tests with intact cell suspensions and intermediates of the citric acid cycle as substrates (Delwiche and Carson 1953), or the observed enzyme activities in cell extracts were extremely low and hard to quantify (Bonartseva et al. 1973). In our hands, no indication of 2-oxoglutarate dehydrogenase could be obtained, either of alternative enzymes reducing other electron acceptors such as ferredoxin (assayed with benzyl viologen), or decarboxylating oxoglutarate to succinate semialdehyde. However, we found $\mathrm{NADP}^{+}$-dependent succinate semialdehyde dehydrogenase activity. Subsequent studies with radiolabeling experiments indicated that 4-aminobutyrate was an early labeling intermediate, together with citric acid cycle intermediates and their amination products. Proof of 2-oxoglutarate: 4-aminobutyrate aminotransferase and glutamate decarboxylase finally completed the reaction cycle for acetate oxidation as depicted in Fig.4. Obviously, enzymes normally active in fermentation of amino acid residues were recruited here for acetate oxidation.

Lack of enzymes of the glyoxylate cycle explains why acetate oxidation by $P$. freudenreichii followed linear rather than exponential kinetics, different from glycerol, lactate, or propionate oxidation under the same conditions (Emde and Schink 1990). In fact, cell matter increased during acetate oxidation only by a factor of two or less, which could easily be explained by exhaustion of oxaloacetate due to, for example, amino acid synthesis and assimilation.

The cell yields obtained with acetate and hexacyanoferrate (III) during growth under optimal conditions were in the range of $23.4-28.4 \mathrm{~g}$ cell mass per mol of acetate oxidized, indicating that 2-3 mol ATP could be synthesized per reaction run (Stouthamer 1979). Earlier studies with the three-electrode poised-potential cultivation system and hexacyanoferrate as electron carrier indicated that the electrons are transferred to the acceptor probably at the redox level of menaquinone $\left(\mathrm{E}_{0}^{\prime}=\right.$ $-74 \mathrm{mV}$ ). The overall reaction of acetate oxidation with electron release at this redox potential according to the equation

$\mathrm{C}_{2} \mathrm{H}_{3} \mathrm{O}_{2}^{-}+2 \mathrm{H}_{2} \mathrm{O} \rightarrow 2 \mathrm{CO}_{2}+7 \mathrm{H}^{+}+8 \mathrm{e}^{-}$

releases a $\Delta \mathrm{G}_{0}^{\prime}=-148 \mathrm{~kJ}$ per mol, which should be sufficient to allow synthesis of at least 2 ATP $(60-70 \mathrm{~kJ}$ per mol ATP under irreversible conditions; Thauer et al. 1977). If acetate activation is accomplished through acetate kinase and phosphate acetyltransferase at the expense of one ATP, and no ATP equivalent is formed by substrate-level phosphorylation in the citric acid cycle, a total of at least three ATP units would need to be formed by electron transport phosphorylation with the NADH and NADPH electrons obtained by oxidation of isocitrate, succinate semialdehyde, and malate to explain the observed growth yields. This is in good agreement with the assumptions made above. 
Acknowledgements The major part of this study was performed in the Department of Microbiology at the University of Tibingen. We are greatly indebted to Prof. Klaus Wegmann, Tübingen, for his help with the short-term labeling experiments and their interpretation. We also want to thank Dr. Rainer Emde for his initial studies on acetate oxidation by this bacterium and for technical help with the electrode cultivation system.

\section{References}

Anfinsen CB (1955) Aconitase from pig heart muscle. In: Colowick SP, Kaplan NO (eds) Methods in enzymology, vol 1. Academic Press, New York, pp 695-698

Bergmeyer HU (1974) Methoden der enzymatischen Analyse, 3rd edn. Verlag Chemie, Weinheim

Bernt E, Bergmeyer HU (1974) Isocitrate dehydrogenase. UV-test. In: Bergmeyer HU (ed) Methoden der enzymatischen Analyse, vol 1, 3rd edn. Verlag Chemie, Weinheim, pp 660-663

Bonartseva GA, Krainova OA, Vorob'eva LI (1973) Pathways of terminal oxidation in propionic acid bacteria. Microbiology $42: 520-525$

Bradford MM (1976) A rapid and sensitive method for the quantitation of microgram quantities of protein utilizing the principle of protein-dye binding. Anal Biochem 72:248-254

Brandis-Heep A, Gebhardt NA, Thauer RK, Widdel F, Pfennig N (1983) Anaerobic acetate oxidation to $\mathrm{CO}_{2}$ by Desulfobacter postgatei. 1. Demonstration of all enzymes required for the operation of the citric acid cycle. Arch Microbiol 136:222-229

Brune A, Schink B (1990) Pyrogallol-to-phloroglucinol conversion and other hydroxyl-transfer reactions catalyzed by cell extracts of Pelobacter acidigallici. J Bacteriol 172:1070-1076

Bryant F, Overell BT (1953) Quantitative chromatographic analysis of organic acids in plant tissue extracts. Biochim Biophys Acta 10:471-476

Dehning I, Schink B (1989) Malonomonas rubra gen. nov. sp. nov., a microaerotolerant anaerobic bacterium growing by decarboxylation of malonate. Arch Microbiol 151:427-433

Delwiche EA, Carson SF (1953) A citric acid cycle in Propionibacterium pentosaceum. J Bacteriol 65:318-321

De Vries W, Van Wyck-Kapteyn WMC, Stouthamer AH (1973) Generation of ATP during cytochrome-linked anaerobic electron transport in propionic acid bacteria. J Gen Microbiol 76: $31-41$

Diekert GB, Thaner RK (1978) Carbon monoxide oxidation by Clostridium thermoaceticum. J Bacteriol 136:597-606

Dixon GH, Kornberg HL (1959) Assay methods for key enzymes of the glyoxylate cycle. Biochem J $72: 3 p$

Emde R, Schink B (1990) Oxidation of glycerol, lactate, and propionate by Propionibacterium freudenreichii in a poised-potential amperometric culture system. Arch Microbiol 153:506512

Emde R, Swain A, Schink B (1989) Anaerobic oxidation of glycerol by Escherichia coli in an amperometric poised-potential culture system. Appl Microbiol Biotechnol 32:170-175

Fonda ML (1985) L-Glutamate decarboxylase from bacteria. In: Meister N (ed) Methods of enzymology, vol 113. Academic Press, New York, pp 26-30
Heath EC, Horecker BL, Smyrniotics PZ, Takagi Y (1958) Pentose fermentation by Lactobacillus plantarum. J Biol Chem 231: 1031-1037

Jakoby WB (1962) Enzymes of $\gamma$-aminobutyrate metabolism (bacterial). In: Colowick SP, Kaplan NO (eds) Methods in enzymology, vol 5. Academic Press, New York, pp 765-778

Kapol R, Storck J, Radler F (1990) 2-Oxoglutarate decarboxylase of Leuconostoc oenos. Folia Microbiol 35:205-208

Platen H, Schink B (1990) Enzymes involved in anaerobic degradation of acetone by a denitrifying bacterium. Biodegradation $1: 243-251$

Reed LJ, Mukherjee BB (1969) $\alpha$-Ketoglutarate-dehydrogenase complex from Escherichia coli. In: Lowenstein JM (ed) Methods in enzymology, vol 13. Academic Press, New York, pp 5567

Riddles PW, Blakeley RL, Zerner B (1979) Ellman's reagent: 5,5'dithiobis(2-nitrobenzoic acid) - a reexamination. Anal Biochem $94: 75-81$

Rosner B, Schink B (1990) Propionate acts as carboxylic group acceptor in aspartate fermentation by Propionibacterium freudenreichii. Arch Microbiol 155:46-51

Schauder R, Eikmanns B, Thauer RK, Widdel F, Fuchs G (1986) Acetate oxidation to $\mathrm{CO}_{2}$ in anaerobic bacteria via a novel pathway not involving reactions of the citric acid cycle. Arch Microbiol 145: 162-172

Schürmann P (1969) Separation of phosphate esters and algal extracts by thin-layer electrophoresis and chromatography. J Chromatogr 39:507-509

Shiio I, Ujigawa, Takeda K (1980) Presence and regulation of $\alpha$ ketoglutarate dehydrogenase complex in a glutamate-producing bacterium, Brevibacterium flavum. Agric Biol Chem 44 . $1897-1904$

Stams AJM, Kremer DR, Nicolay K, Weenk GH, Hansen TA (1984) Pathway of propionate formation in Desulfobulbus propionicus. Arch Microbiol 139:167-173

Stjernholm R, Flanders F (1962) Metabolism of D-ribose-1-C $\mathrm{C}^{14}$ and $\mathrm{C}^{14}$-labeled D-gluconate in an enzyme system of the genus Propionibacterium. J Bacteriol 84:563-568

Stouthamer AH (1979) The search for correlation between theoretical and experimental growth yields. In: Quayle JR (ed) International review of biochemistry, microbial biochemistry, vol 21. University Park Press, Baltimore, pp $1-47$

Thauer RK, Jungermann K, Decker K (1977) Energy conservation in chemotrophic anaerobic bacteria. Bacteriol Rev 41:100-180

Van Gent-Ruyters MLW, De Vries W, Stouthamer AH (1975) Influence of nitrate on fermentation pattern, molar growth yields and synthesis of cytochrome $b$ in Propionibacterium pentosaceum. J Gen Microbiol 88:36-48

Van Gent-Ruyters MLW, De Meyer FA, De Vries W, Stouthamer AH (1976) Lactate metabolism in Propionibacterium pentosaceum growing with nitrate or oxygen as hydrogen acceptor. Antonie Van Leeuwenhoek 42:217-228

Wood HG (1981) Metabolic cycles in the fermentation by propionic acid bacteria. Curr Top Cell Regul 18:255-287

Zeikus JG, Fuchs G, Kenealy W, Thauer RK (1977) Oxidoreductases involved in cell carbon synthesis of Methanobacterium thermoautotrophicum. J Bacteriol 132:604-613 